\title{
Effect of zirconium addition on the recrystallization behaviour of a commercial Al-Cu-Mg alloy
}

\author{
K T KASHYAP \\ Department of Mechanical Engineering, M.S. Ramaiah Institute of Technology, Bangalore 560 054, India
}

MS received 24 May 2001; revised 24 August 2001

\begin{abstract}
It is well known that the second phase particles have an effect on recrystallization and grain growth behaviour of an alloy. Particularly the bimodal distribution of second phase particles has an effect which is opposite in sense where coarse second phase particles $(>1 \mu \mathrm{m})$ stimulate nucleation while fine particles exhibit Zener drag.

In the literature, the effect of zirconium addition to aluminium alloys has been well documented in order to produce superplasticity by giving ultra fine grain size to the alloy. Addition of zirconium produces $\mathrm{Al}_{3} \mathrm{Zr}$ particles which pin the grain boundaries during recrystallization and grain growth.

In the present work, zirconium was added to a commercial $\mathrm{Al}-\mathrm{Cu}-\mathrm{Mg}$ alloy and by heat treatment $\mathrm{Al}_{3} \mathrm{Zr}$ particles were precipitated and after forging, the grain size was an order of magnitude lower than the alloy without zirconium.

Transmission electron microscopy was employed to characterize the second phase particles, i.e. $\mathrm{Al}_{3} \mathrm{Zr}$ particles and found to be rod shaped and identified to be cubic ordered $L 1_{2}$ phase with a lattice parameter of $0.408 \mathrm{~nm}$. Further, it was observed that fine $(100 \mathrm{~nm}) \mathrm{Al}_{3} \mathrm{Zr}$ particles promote only continuous recrystallization which is polygonization of subgrains and subgrain growth.

It was found that the fine dispersion of $\mathrm{Al}_{3} \mathrm{Zr}$ particles inhibits both recrystallization and grain growth in the commercial Al-Cu-Mg alloy.
\end{abstract}

Keywords. $\mathrm{Al}-\mathrm{Cu}-\mathrm{Mg}$ alloy; recrystallization; $\mathrm{Al}_{3} \mathrm{Zr}$ particles; $\mathrm{Zr}$ addition.

\section{Introduction}

It is well known that recrystallization behaviour of an alloy is altered by the presence of second phase particles. Coarse second phase particles $(>1 \mu \mathrm{m})$ stimulate recrystallization by a mechanism known as particle stimulated nucleation (PSN) as shown by Humphreys (1977). However, fine particles $(<1 \mu \mathrm{m})$ inhibit primary recrystallization and grain growth as described by Nes (1976). The drag exerted by second phase particles is known as Zener drag as quoted by Smith (1948). It is found by Doherty and Martin (1962) that as the spacing between second phase particles increases, grain size drops and time to $50 \%$ recrystallization drops. Doherty and Martin (1962) have also shown that as $F_{\mathrm{v}} / r$ is increased, nucleation rate increases and at a critical $F_{\mathrm{v}} / r$, nucleation rate drops to low values. Precipitation during recrystallization alters the recrystallization behaviour which has been reviewed by Hornbogen and Koster (1978).

Importantly, a bimodal distribution of second phase particles affects the recrystallization behaviour in a peculiar way as described by Nes (1976). Coarse constituent particles stimulate nucleation of recrystallization whereas fine second phase particles inhibit recrystalli- zation. This opposite effect of second phase particles in controlling recrystallization behaviour is important in commercial aluminium alloys.

The parameter which controls this behaviour is $F_{\mathrm{v}} / r$, where $F_{\mathrm{v}}$ is the volume fraction of fine second phase particles and $r$, the average radius of the fine particles. Increasing $F_{\mathrm{v}} / r$ of fine particles increases the critical radius of the coarse particles to stimulate PSN as shown by Nes (1985).

Based on the models developed by Nes (1985), Wert and Austin (1985) and Nes and Hutchinson (1989), the main parameter which determines the final grain size after annealing an alloy which contains a volume fraction $F_{\mathrm{v}}$ of small particles of mean radius $r$ is $F_{\mathrm{v}} / r . F_{\mathrm{v}} / r$ affects the Zener drag given by

$$
P_{\mathrm{Z}}=\frac{3 F_{\mathrm{v}} \gamma}{2 r}
$$

where $P_{\mathrm{Z}}$ is the Zener drag, $\gamma$ the surface energy of the high angle boundary, $F_{\mathrm{v}}$ the volume fraction of fine second phase particles, $r$ the mean radius of second phase particles. $F_{\mathrm{v}} / r$ also affects the number of viable recrystallization nuclei given by 


$$
d_{\mathrm{g}}=\frac{4 \gamma}{P_{\mathrm{D}}-P_{\mathrm{Z}}}=\frac{4 \gamma}{\frac{\rho G b^{2}}{2}-\frac{3 F_{\mathrm{v}} \gamma}{2 r}},
$$

where $d_{\mathrm{g}}$ is the critical particle size for the growth of the viable nucleus, $\gamma$ the surface energy of the boundary, $P_{\mathrm{D}}$ the driving pressure, $P_{\mathrm{Z}}$ the Zener drag, $\rho$ the dislocation density, $G$ the shear modulus and $b$ the burger's vector.

Finally $F_{\mathrm{v}} / r$ affects grain growth by

$$
D_{\lim }=\frac{4 r}{3 F_{\mathrm{v}}} \text {. }
$$

Grimes et al (1976), Watts et al (1976) and Matsuki et al $(1976,1977)$ have shown that zirconium addition to aluminium alloys makes them super plastic by stabilizing ultra fine grain size by the effect of fine $\mathrm{Al}_{3} \mathrm{Zr}$ particles. $\mathrm{Al}_{3} \mathrm{Zr}$ particles inhibit discontinuous recrystallization and promote only continuous recrystallization and fine particles also inhibit grain growth.

In the present work, zirconium was added to a commercial $\mathrm{Al}-\mathrm{Cu}-\mathrm{Mg}$ alloy to inhibit recrystallization and grain growth. The bimodal distribution of $\mathrm{Al}_{3} \mathrm{Zr}$ and the constituent particles of $\mathrm{Fe}-\mathrm{Mn}$ phase have been studied for their effects on recrystallization behaviour and grain growth behaviour after commercial processing. Detailed transmission electron microscopic characterization of $\mathrm{Al}_{3} \mathrm{Zr}$ particles has also been carried out.

\section{Experimental}

The commercial aluminum alloy, V-65 was d.c. cast with zirconium addition of $0.16 \% \mathrm{Zr}$ and without zirconium. Table 1 shows chemical composition of the alloys. The d.c. cast billet was homogenized at $490^{\circ} \mathrm{C}$ for $24 \mathrm{~h}$ and furnace cooled and then a low temperature treatment was given at $300^{\circ} \mathrm{C}$ for $48 \mathrm{~h}$ and air cooled. Electrical conductivity increased from $30 \%$ IACS in the cast state to $41 \%$ IACS after $300^{\circ} \mathrm{C}$ treatment indicating precipitation from the supersaturated d.c. cast ingot. The billets were deformed by the C-process and forged in a closed die forging equipment at $430^{\circ} \mathrm{C}$.

Samples were sectioned and polished by conventional mechanical methods and etched in Keller's reagent. Samples were examined under optical microscope and scanning electron microscope (LEO 440). Samples were polished with Struers double jet polisher with 10\% perchloric acid, balance methanol solution and thin foils were examined on a transmission electron microscope
(JEOL 100KV microscope). Volume fractions and particle sizes of second phase particles were determined by image analysis.

\section{Results and discussion}

The d.c. cast billet (alloy V-65) which was homogenized and precipitated showed a conductivity increase from $30 \%$ IACS to $41 \%$ IACS from the as cast state to fully precipitated state, respectively.

Figure 1 shows the backscattered electron image of the alloy after low temperature treatment. The fine and coarse particles which look bright are $\mathrm{Fe}-\mathrm{Mn}$ phase. Table 2 shows the SEM-EDX results of this phase. Image analysis was carried out and the volume fraction of these particles is found to be 0.05 with a mean radius of particles to be $0.37 \mu \mathrm{m}$. $\mathrm{Al}_{3} \mathrm{Zr}$ particles are also present but it cannot be identified on the SEM or on the optical microscope.

Figures 2 and 3 show the microstructure of the alloy with $0.16 \% \mathrm{Zr}$ at two different magnifications. The recrystallized grain size is of the order of 4-5 $\mu \mathrm{m}$.

Figures 4 and 5 show the microstructure of the alloy without $\mathrm{Zr}$ at two different magnifications. The recrystallized grain size is of the order of 50-60 $\mu \mathrm{m}$. All these microstructures were taken after homogenization, Cdeformation and forging.

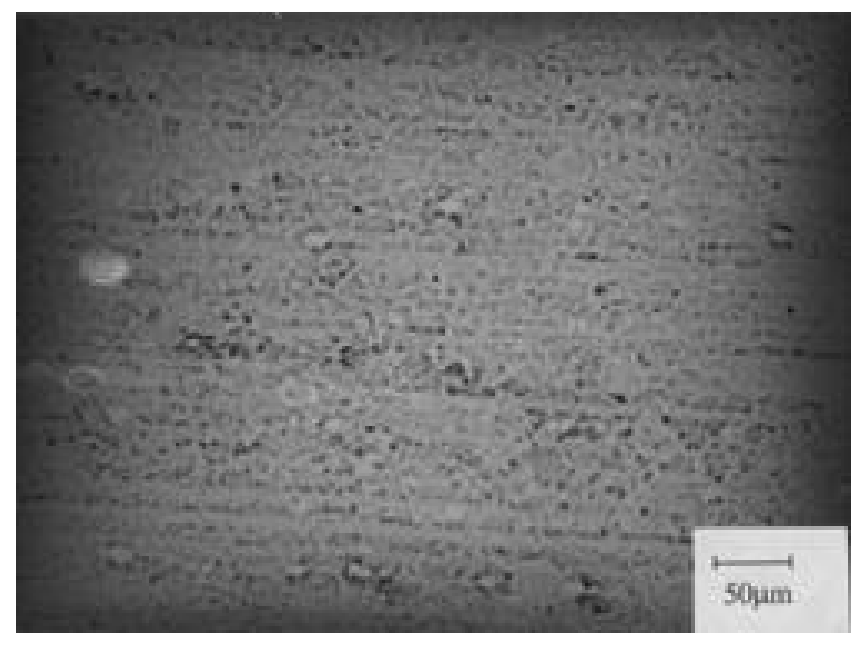

Figure 1. Backscattered electron image of the alloy after low temperature treatment.

Table 2. SEM-EDX results of the Fe-Mn phase (at \%).

\begin{tabular}{cccc}
\hline $\mathrm{Mn}$ & $\mathrm{Fe}$ & $\mathrm{Cu}$ & $\mathrm{Al}$ \\
\hline 0.36 & 0.54 & 10.81 & 88.29 \\
\hline
\end{tabular}

Table 1. Chemical composition of V-65 alloys (in wt \%).

\begin{tabular}{cccccccc}
\hline & $\mathrm{Cu}$ & $\mathrm{Mg}$ & $\mathrm{Si}$ & $\mathrm{Fe}$ & $\mathrm{Mn}$ & $\mathrm{Zr}$ & $\mathrm{Al}$ \\
\hline Alloy A & $4 \cdot 5$ & $0 \cdot 19$ & $0 \cdot 13$ & $0 \cdot 17$ & $0 \cdot 40$ & $0 \cdot 16$ & $\mathrm{Bal}$ \\
Alloy B & 4.5 & $0 \cdot 19$ & $0 \cdot 13$ & $0 \cdot 17$ & $0 \cdot 40$ & - & $\mathrm{Bal}$ \\
\hline
\end{tabular}


There is a dramatic reduction of grain size $(4-5 \mu \mathrm{m})$ with $\mathrm{Zr}$ addition as compared to the alloy without $\mathrm{Zr}$ addition $(50-60 \mu \mathrm{m})$. The $\mathrm{Al}_{3} \mathrm{Zr}$ particles are not resolved on the SEM either in the secondary electron imaging or backscattered electron imaging. Therefore transmission electron microscopy of thin foils was carried out.

Figures 6 and 7 show the bright field TEM image of the precipitates. Figures 8 and 9 show the electron diffraction patterns. The rod shaped precipitates were identified to be $\mathrm{Al}_{3} \mathrm{Zr}$ particles with a ordered $L 1_{2}$ structure with a lattice parameter of $4.08 \AA$. The average particle size is found to be $100 \mathrm{~nm}$. It is also observed from the bright field TEM images (figures 6 and 7) that the subgrain structure is pinned by rod shaped $\mathrm{Al}_{3} \mathrm{Zr}$ particles. This means only continuous recrystallization is promoted by the fine dispersion of $\mathrm{Al}_{3} \mathrm{Zr}$ particles.

This is the reason why a fine grain size is obtained by zirconium addition as shown in figures 2 and 3

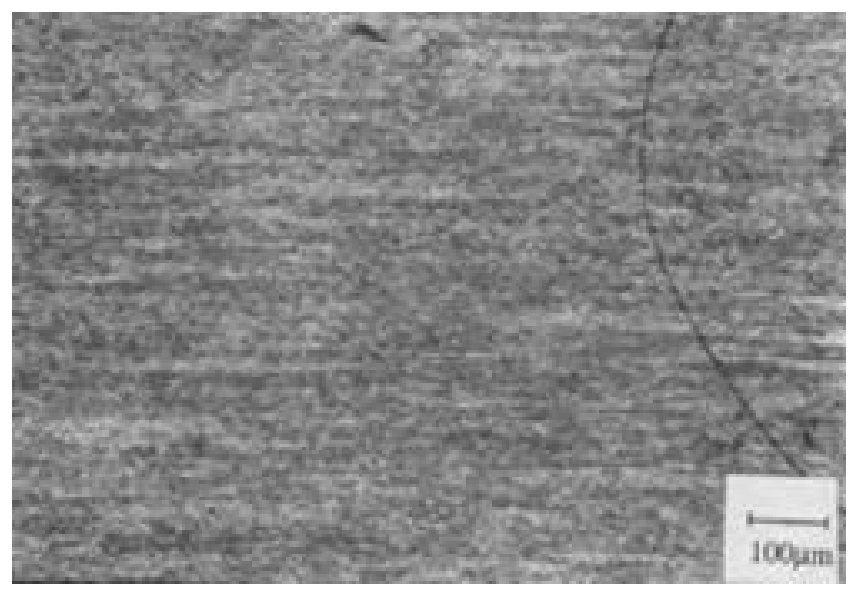

Figure 2. Microstructure of the alloy with Zr. Partially recrystallized (alloy A) showing fine grains.

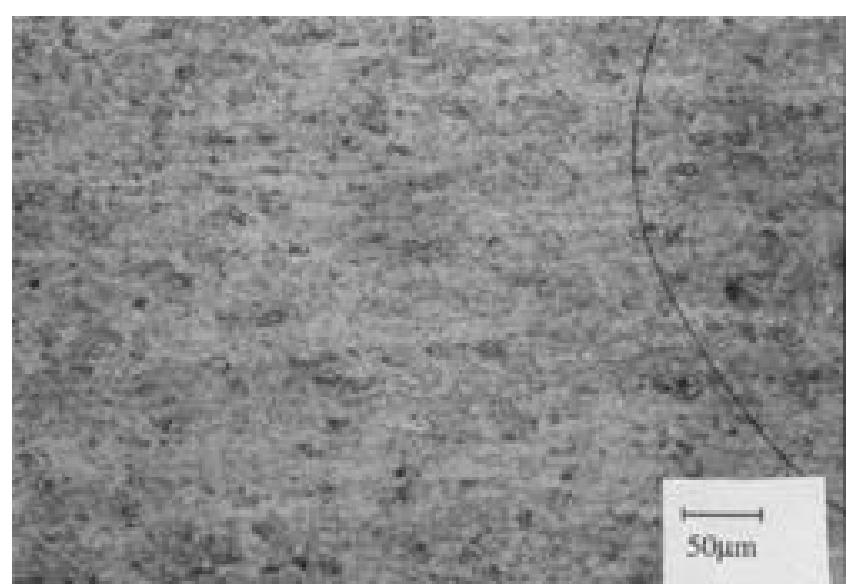

Figure 3. Microstructure of the alloy with Zr. Partially recrystallized (alloy A) at a higher magnification. at two different magnifications as opposed to figures 4 and 5 wherein without zirconium addition, the grain size is coarse in the alloy after the same treatment. The volume fraction of $\mathrm{Al}_{3} \mathrm{Zr}$ particles was estimated from theoretical calculations as shown below.

\begin{tabular}{ll}
\hline $\begin{array}{l}\text { Alloy composition } \\
(w t \%)\end{array}$ & $\begin{array}{r}\text { Atomic } \\
\text { weight }\end{array}$ \\
\hline $4.5 \mathrm{Cu}$ & 63.54 \\
$0.19 \mathrm{Mg}$ & 24.31 \\
$0.13 \mathrm{Si}$ & 28.09 \\
$0.17 \mathrm{Fe}$ & 55.85 \\
$0.40 \mathrm{Mn}$ & 54.94 \\
$0.16 \mathrm{Zr}$ & 91.22 \\
$94.51 \mathrm{Al}$ & 26.93 \\
\hline
\end{tabular}

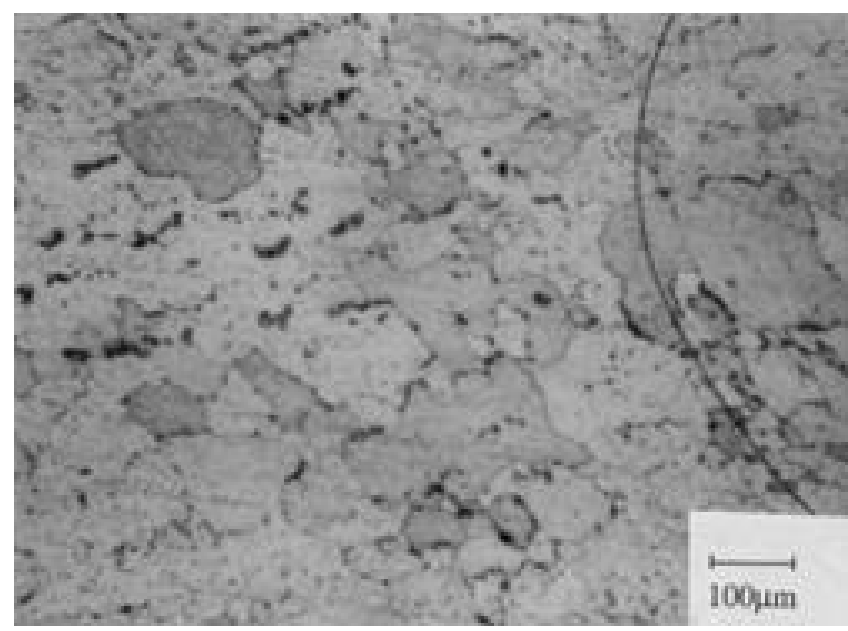

Figure 4. Microstructure of the alloy without Zr. Alloy B fully recrystallized followed by grain growth coarse grain size.

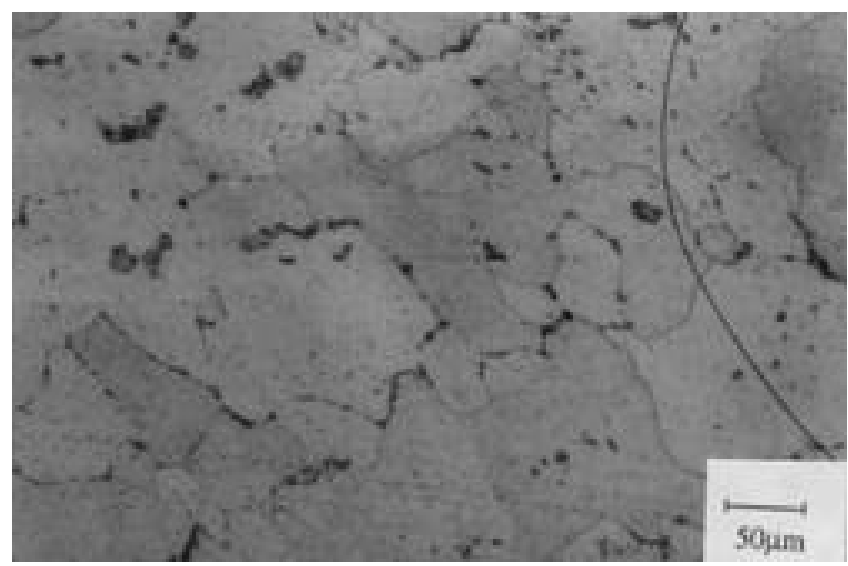

Figure 5. Microstructure of the alloy without Zr. Alloy B fully recrystallized followed by grain growth. Higher magnification photograph. 
Atom fraction of zirconium,

$$
\begin{aligned}
& =\frac{\frac{0 \cdot 16}{91 \cdot 22}}{\frac{4 \cdot 5}{63 \cdot 54}+\frac{0 \cdot 19}{24 \cdot 31}+\frac{0 \cdot 13}{28 \cdot 09}+\frac{0 \cdot 17}{55 \cdot 85}+\frac{0 \cdot 4}{54 \cdot 94}+\frac{0 \cdot 16}{91 \cdot 22}} \\
& =0 \cdot 000486 .
\end{aligned}
$$

At. fraction of $\mathrm{Zr}=0.000486$.

There are 3 atoms of $\mathrm{Al}$ and 1 atom of $\mathrm{Zr}$ in one molecule of $\mathrm{Al}_{3} \mathrm{Zr}$ which means it has 4 atoms to 1 atom of zirconium. If the size of the unit cell of $\mathrm{Al}_{3} \mathrm{Zr}$ is the same as that of aluminium which is to a very high degree of accuracy, then the atomic fraction of zirconium is the same as the volume fraction.

$$
\begin{aligned}
& F_{\mathrm{v}}=4 \times 0.000486=0.00194, \\
& r=100 \mathrm{~nm}=0.1 \mu \mathrm{m} .
\end{aligned}
$$

However, there are bimodal dispersions (Fe-Mn and $\mathrm{Al}_{3} \mathrm{Zr}$ phases) of second phase particles.

$\mathrm{Fe}-\mathrm{Mn}$ phase, $F_{\mathrm{v}}=0.05$,

$$
r=0.37 \mu \mathrm{m} \text {. }
$$

$\mathrm{Al}_{3} \mathrm{Zr}$ phase, $\quad F_{\mathrm{v}}=0.00194$

$$
r=0 \cdot 1 \mu \mathrm{ms} \text {. }
$$

The zener drag is given by

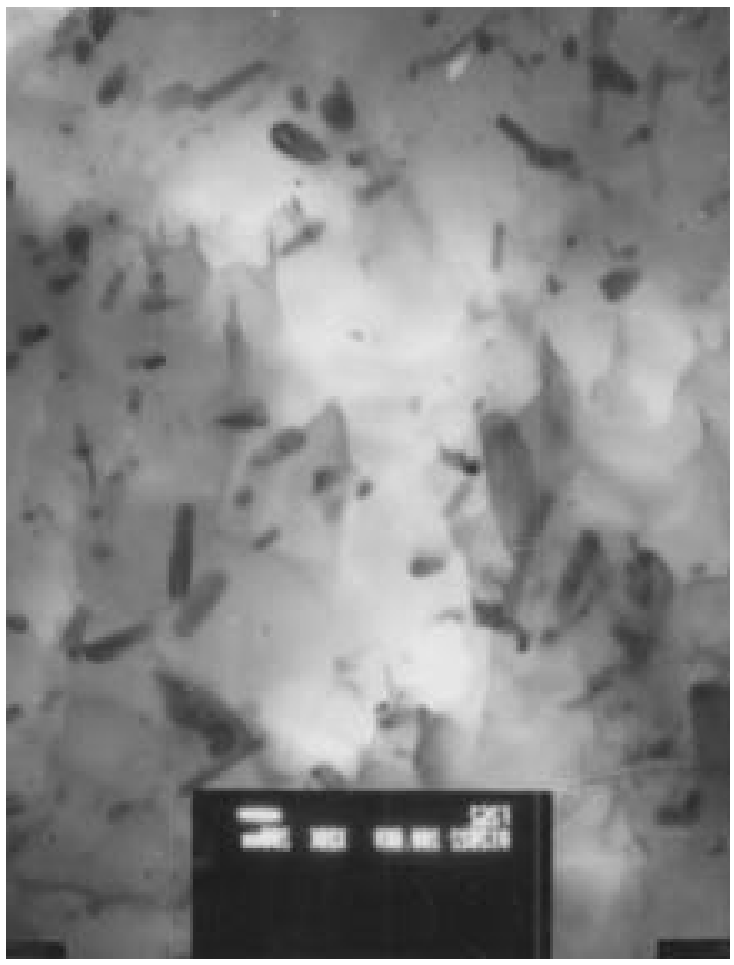

Figure 6. Bright field TEM image of the $\mathrm{Al}_{3} \mathrm{Zr}$ particles which are rod shaped. Subgrain boundaries are pinned.

$$
P_{\mathrm{Z}}=\frac{3 F_{\mathrm{v}} \gamma}{2 r}
$$

Total zener drag

$$
P_{\mathrm{Z} \text { total }}=\frac{3 F_{\mathrm{v} 1} \gamma}{2 r_{1}}+\frac{3 F_{\mathrm{v} 2} \gamma}{2 r_{2}} \text {. }
$$

Equating driving force grain curvature to zener drag

$$
\begin{aligned}
\frac{2 \gamma}{D} & =\frac{3 F_{\mathrm{v} 1} \gamma}{2 r_{1}}+\frac{3 F_{\mathrm{v} 2} \gamma}{2 r_{2}}, \\
D_{\lim } & =\frac{2}{\frac{3 F_{\mathrm{v} 1} \gamma}{2 r_{1}}+\frac{3 F_{\mathrm{v} 2} \gamma}{2 r_{2}}}, \\
D_{\lim } & =\frac{\frac{2 \times 0 \cdot 05}{2 \times 0.37}+\frac{3 \times 0 \cdot 00194}{2 \times 0 \cdot 1}}{2 \times 1} \\
& =8.6 \mu \mathrm{ms} .
\end{aligned}
$$

With a single dispersion i.e. without $\mathrm{Al}_{3} \mathrm{Zr}$

$$
D_{\lim }=\frac{4 r}{3 F_{\mathrm{v}}}=\frac{4 \times 0 \cdot 37}{3 \times 0 \cdot 05}=10 \mathrm{ìm} \text {. }
$$

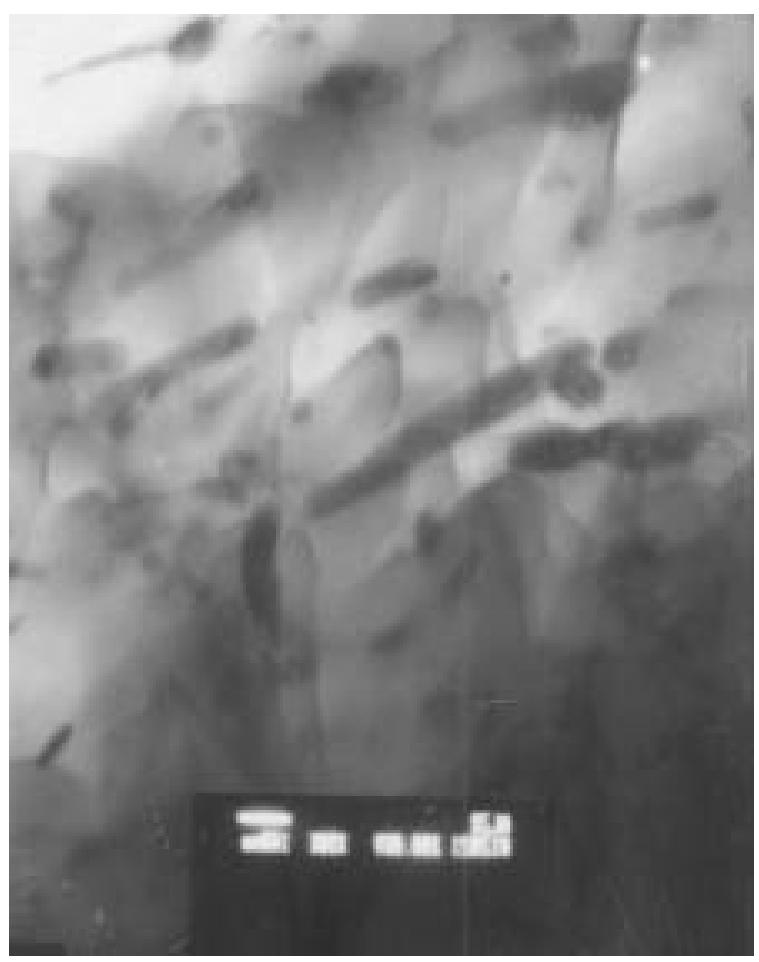

Figure 7. Bright field TEM image of the $\mathrm{Al}_{3} \mathrm{Zr}$ particles (higher magnification). Subgrain boundaries are seen. 


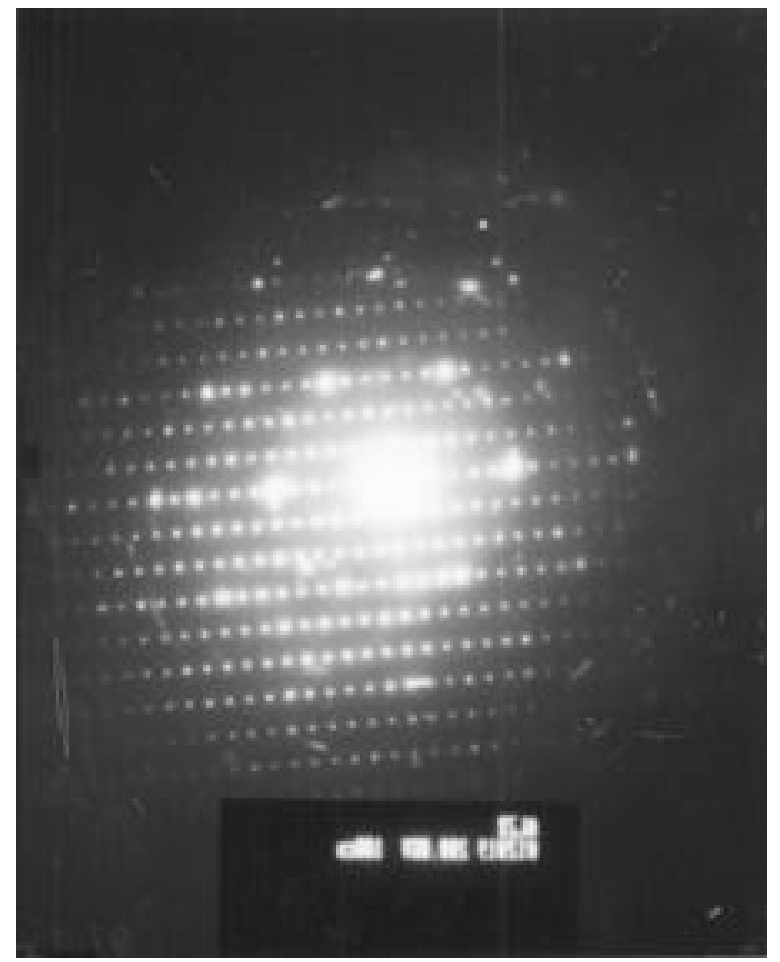

Figure 8. Electron diffraction pattern of $\mathrm{Al}_{3} \mathrm{Zr}$ particles. Ordered $L 1_{2}$ structure with $a=0.408 \mathrm{~nm}$.

In the homogenized and precipitated alloy, the recrystallized grain size is $4-5 \mu \mathrm{m}$ which correlates with $D_{\lim }$ Zener $(8.6 \mu \mathrm{m})$. The alloy without zirconium had a grain size of $50-60 \mu \mathrm{m}$. But this analysis ignores the fact that the $\mathrm{Al}_{3} \mathrm{Zr}$ phase is coherent with the matrix and so should exert a larger drag than the incoherent phase. Since the volume fraction of $\mathrm{Al}_{3} \mathrm{Zr}$ particles is low, the effect of $\mathrm{Fe}-\mathrm{Mn}$ phase is predominant.

However, although the volume fraction of $\mathrm{Al}_{3} \mathrm{Zr}$ particles in the microstructure is low, it has a pronounced effect on recrystallization as seen in figures 6 and 7 which show subgrains in the background which is pinned by rod shaped $\mathrm{Al}_{3} \mathrm{Zr}$ particles.

Nucleation of recrystallization is associated with subgrain coalescence as shown by Doherty and Cahn (1972) by glide and climb of dislocations which form low angle boundaries adjacent to neighbouring high angle boundaries. Fine $\mathrm{Al}_{3} \mathrm{Zr}$ particles inhibit this rearrangement of dislocations and also prevent migration of high angle boundaries. Thus nucleation of recrystallization is retarded. Only continuous recrystallization is promoted wherein polygonization and subgrain growth are favoured.

Finally, grain growth is also retarded by the fine dispersion of $\mathrm{Al}_{3} \mathrm{Zr}$ particles. Therefore, the fine dispersion of $\mathrm{Al}_{3} \mathrm{Zr}$ particles has an effect on primary recrystallization and grain growth following primary recrystallization.

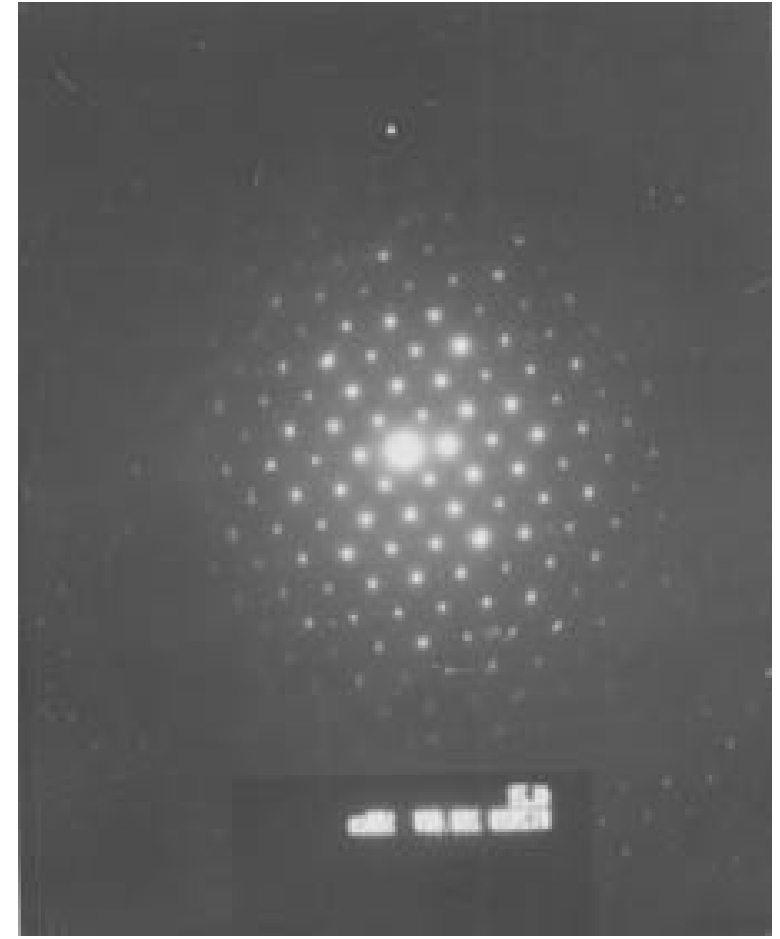

Figure 9. Electron diffraction pattern of $\mathrm{Al}_{3} \mathrm{Zr}$ particles. Ordered $L 1_{2}$ structure with $a=0.408 \mathrm{~nm}$.

This effect is consistent with the study of Watts et al (1976) where they added $0.5 \% \mathrm{Zr}$ to $\mathrm{Al}-\mathrm{Cu}$ alloy to achieve a very fine grain size to allow superplasticity at high temperature.

\section{Conclusions}

(I) TEM results show that $\mathrm{Al}_{3} \mathrm{Zr}$ particles pin subgrain boundaries and promote continuous recrystallization.

(II) As a result of which the grain size after recrystallization has dropped to $5 \mu \mathrm{m}$ from $60 \mu \mathrm{m}$ after addition of zirconium to the alloy and giving it low temperature treatment.

(III) Fe-Mn phase is produced during d.c. casting as coarse $(>1 \mu \mathrm{m})$ particles as a result of solidification. These particles promote PSN. But the fine particles precipitated together with $\mathrm{Al}_{3} \mathrm{Zr}$ exhibits Zener drag and controls recrystallization and grain growth.

(IV) Fine $\mathrm{Al}_{3} \mathrm{Zr}$ and $\mathrm{Fe}-\mathrm{Mn}$ particles control recrystallization and grain growth in this commercial $\mathrm{Al}-\mathrm{Cu}-\mathrm{Mg}$ alloy.

\section{References}

Doherty R D and Cahn R W 1972 J. Less Common Metals 28 279 
Doherty R D and Martin J W 1962 J. Inst. Metals 91332

Grimes R, Stowell M J and Watts B M 1976 Met. Technol. 3154

Hornbogen K and Koster U 1978 in Recrystallization of metallic materials (ed.) F Haaesner (Stuttgart, Germany: Riederer Verlag Gmbh)

Humphreys F J 1977 Acta Metall. 251323

Matsuki K, Netani Y, Yamada M and Murakani Y 1976 Met. Sci. 10235

Matsuki K, Moriba H, Yamada M and Murakani Y 1977 Met. Sci. 11156
Nes E 1976 Acta Metall. 24391

Nes E 1985 Proc. symp. on microstructural control during processing of aluminium alloys, New York, p. 95

Nes E and Hutchinson W B 1989 Proc. 10th int. Riso symp. (ed.) Bilde Sorensen (Roskilde, Denmark: Riso National Laboratories) p. 233

Smith C S 1948 Trans. Metall. Soc. AIME 15175

Watts B M, Stowell M J, Baikie B L and Owen D G E 1976 Met. Sci. 10 189, 198

Wert J A and Austin L K 1985 Met. Trans. A19 617 